\title{
TEORIA DA URBANIZAÇÃO PARA OS PAÍSES POBRES: ELEMENTOS DA OBRA DE MILTON SANTOS
}

\author{
Amélia Luisa Damiani“
}

Que os países pobres estejam inseridos, de alguma forma, e cada vez mais, no mundo, ou melhor, na mundialização, é inconteste.

Que, no entanto, sua interpretação é carregada de pré-concepções advindas dos países desenvolvidos, os que sugerem modelos clássicos de compreensão dos fenômenos políticos, econômicos e sociais, também, é uma evidência e uma aporia na concepção da história desses países. Essa redução da história desses países e de sua especificidade pode chegar, nos extremos da vulgarização, a uma maneira evolutiva, linear de examinar sua história: seremos, o que são, hoje, os países desenvolvidos, se eliminarmos nossa patologia econômico-social intrínseca, a partir de políticas internacionais, nascidas do conserto do Sistema de Estados. Estratégias, nessa direção, evoluíram, principalmente, depois da Segunda Guerra Mundial. Evidentemente, uma literatura alternativa, boa parte da qual, nascida nos países pobres, vem se contrapor a esses termos redutores, por mais de meio século. Mas, existem teias entre as interpretações "clássicas" e aquelas singulares aos países pobres, e a revisão constante dessa literatura alternativa marca a história do conhecimento desses países. Como, por exemplo, identificar modos de produção feudais ou pré-capitalistas nesses países e, depois, pôr à prova essa interpretação.

A persistência do entendimento "clássico", como modelo de interpretação dos países pobres, paira como fantasma e armadilha na justificativa da pobreza desses países, como legado do seu atraso. E, mais ainda, como figura de um mundo pobre, porque distante da riqueza, diferente da riqueza, no limite, no sentido de não relacionado com ela, conveniente interpretação das formas de exploração do trabalho a nível internacional.

É possível imaginar que tais interpretações simplistas persistam?

Claro! Elas alimentam, inclusive, o turismo, essa indústria recente, através da mistura entre o exótico e o atrasado, ou a pobreza espetacular, quase mítica. A falência da relação entre desenvolvimento técnico e segurança e felicidade, acabam por enaltecer o outro desse desenvolvimento.

E, ainda, de outra forma, vejamos uma das raízes dessa compreensão: a de um crescimento populacional superior ao crescimento econômico. Os países pobres se definiriam por esse desequilíbrio, numa versão malthusiana de sua pobreza. Dentro e fora da geografia, essa versão malthusiana de sua pobreza se consolidou, e, hoje, renova-se. Admitese, cada vez mais, que a modernização tecnológica nos atingiu, mas ela apenas reproduz o antigo paradigma, agora, através da leitura de um desemprego estrutural, combinado a um aumento inequívoco da população, daí a nova literatura sobre a exclusão. Na essência, a antiga explicação se reforça: um crescimento populacional exorbitante para os limites do emprego moderno e de capital intensivo. As cidades, inchadas e pobres, apareceram e aparecem como continentes privilegiados dessa explicação.

(*) Trabalho apresentado no Encontro Internacional "O Mundo do Cidadão - Um Cidadão do Mundo", realizado em São Paulo, no Departamento de Geografia, da Universidade de São Paulo, em outubro de 1996. 
Então, cedo se reconhece uma especificidade dos países pobres, que não é exatamente uma teoria a seu respeito, pois está inserida na "explicação clássica do capitalismo", inclusive, de uma forma dedutiva: um crescimento modesto, embora real, frente aos atrasados modos de reprodução da população. Jamais foi alternativa concreta, e se configurou como uma teoria crítica sobre os países pobres, nestes termos, subdesenvolvidos, pois, justificaram a inserção do grande capital multinacional, a partir de subsídios de toda ordem, bem como a interferência nos modos de vida de sua população, como verdadeiro processo educativo. Estes são os termos da reprodução ampliada do capital no mundo: modernizando a estrutura produtiva e a de consumo e destruindo hábitos e costumes "atrasados". Valeu-se de estratégias políticas cada vez mais ostensivas, dependentes do conserto do Sistema dos Estados, que aparece sob a égide de organizações mundiais e políticas sociais.

Como a obra do Prof. Milton Santos aparece diante deste preâmbulo?

Não é como obra acabada, inclusive, porque ele está vivo e continua refletindo intensamente essa questão. Mas como um desafio intelectual na configuração de uma teoria crítica sobre os países pobres, debruçada, especialmente, na explicação de sua urbanização, que se combina com uma militância ativa, junto à intelectualidade dos países desenvolvidos e subdesenvolvidos, acordando-a para uma outra compreensão dos países pobres. Seu reconhecimento internacional prova a amplitude dessa cruzada.

Sua compreensão não é definitiva, vem marcada pelos avanços e equívocos da época que vive, da produção científica à sua disposição, mas também por uma criatividade, uma construção ímpar, diante das opções científicas e filosóficas que adotou. Privilegia a leitura estrutural, ou sistêmica, que lhe valeu a compreensão de dois circuitos da economia urbana desses países, cuja relação complexa tenta desvendar, elucidando, no percurso, as possíveis armadilhas da interpretação, diante do vigor e da preponderância dos modelos de compreensão vigentes sobre os países pobres, alimentados por estatísticas oficiais mundializadas, que mascaram sua especificidade. $\mathrm{Na}$ análise, o desvendamento do processo produtivo e o da estrutura de consumo são primordiais. Essa relação deve ser buscada com acuidade, pois ela revelaria o que a explicação oficial dissimula.

Enfrenta a relação "clássica", na explicação do subdesenvolvimento, entre crescimento econômico e crescimento populacional, e não dilui sua explicação numa versão malthusiana, admitindo, inclusive, que o crescimento econômico supere o crescimento populacional nas grandes cidades de países pobres, à base de uma economia urbana segmentada, que se trata de desvendar. O exemplo da metrópole de São Paulo sugere-lhe essa possibilidade.

Estamos, então, a caminho dẹ uma teoria crítica sobre a urbanização nos países pobres, alternativa aos modelos consolidados e demasiadamente inseridos nas estratégias políticas e econômicas de exploração dos países pobres.

Subvertendo as datas da produção científica do prof. Milton Santos e guardando uma interpretação possível de alguns elementos de sua construção, coloco, num primeiro momento, em questão o papel desempenhado pelo planejamento, dentre as causas do subdesenvolvimento e da pobreza no Terceiro Mundo. Terceiro Mundo, praticamente, inventado no interior da aventura da dominação, que sugere, como forma de desenvolvimento necessária, a imposição do capital internacionalizado por toda parte. Sob a égide da eficiência e da racionalidade, esses países são alvo não só de modelos de produção, como de modelos de consumo, embalados pela idéia positivista de progresso. A ciência regional e o planejamento se fundem, numa visão pragmática, visando racionalizar a estrutura interna de dominação e dependência: modernizar o setor tradicional, melhorar as infra-estruturas locais e constituir novos padrões de organização de atividades econômicas, promovendo a entrada de capi- 
tal e sua difusão no espaço. 0 planejamento espacial ganha importância cada vez maior coum a internacionalização do capital. Quanto à urbanictạăio, o que essa difusão sugeriria, como resultado, e, ao mesmo tempo, como condiçào?

A desintegração de economias regionais e com isso a concentração urbana: o fenômeno da macrocefalia. Cidades populosas e áreas rurais modernizadas são parte do projeto de penetração do capital, assim configurado. 0 que em certa literatura aparece como um dado, na realidade, tratou-se de estratégias, corroboradas, exatamente, por essa literatura. Falamos da segunda metade deste século e da pobreza planejada no interior desse processo. Como?

Entre outros procedimentos e politicas, admitindo que a condução da economia dessa maneira era possível mediante investimentos públicos que privilegiassem gastos de infra-estrutura às expensas dos investimentos sociais. Diante dessas estratégias, e do reconhecimento da importância do espaço no seu interior, a alternativa é a de uma geografia heróica, urgente, a ser constituída, como contraposto, que desvendasse faces desse conhecimento-ideologia. ${ }^{1}$ A observar que a economia regional, o planejamento espacial formaram, também, uma tecnoburocracia em desenvolvimento, juntando economistas, arquitetos, geógrafos, entre outros, com a tarefa de dar sustentação às políticas emergentes, que cedo conformou os discursos e as justificativas objetivas e, pretensamente, racionais e progressistas do estado ditatorial, um exemplo brasileiro, que se repete em outros países, uma alternativa imposta ao assalto às universidades. ${ }^{2}$ Existiu, é claro, toda ordem de resistência.

O poder público, principalmente a partir dos anos 60 , exerce um papel ativo na produção da cidade, a cidade do capital monopolista ou oligopolista. Quanto às cidades maiores, e o sentido é o da concentração espacial, chegamos às metrópoles corporativas. O Banco Nacional da Habitação, no caso brasileiro, foi eficaz na formação territorial da cidade corporativa, pondo-se ao serviço da unifica- ção de capitais necessários aos grandes investimentos em infra-estrutura. Um equipamento seletivo do território faz derivar uma urbanização corporativa, juntando a modernização do meio ambiente, favorecendo as grandes empresas, e se há êxito das reivindicações dos grupos sociais, ele depende de pressões corporativas, envolvendo, especialmente, as camadas sociais hegemônicas. ${ }^{3}$

Fazendo uma digressão, a partir de meu trabalho particular com a questão das políticas estatistas sobre o urbano, admito, completando o raciocínio do prof. Milton Santos, que os investimentos em obras urbanas, racionalizando e centralizando o controle de sua produção, ao mesmo tempo, retirando-lhe o caráter de serviços públicos subsidiados e localizados, na década de 70 , são componentes da eficiência relativa e dos termos da produção de grandes conjuntos habitacionais. Quando o investimento habitacional atinge camadas populares, de forma mais abrangente, o faz, num primeiro momento, no final dos anos 70 e no início dos anos 80 , e é possível examinar a atualidade dessa política, conscientemente, criando uma alternativa política dentro da ordem, nos termos do desenvolvi-

(1) A análise remete à interpretação de Milton Santos presente em Economia Espacial: Críticas e Alternativas, São Paulo, Hucitec, 1979.

(2) "As teorias de planejamento urbano e regional raramente decorrem de situações reais que se deseja modificar. Elas se apresentam muito mais como portadoras de um modelo a impor. Esse modelo é, mais freqüentemente, trazido dos países do centro onde são elaboradas para servir a interesses que raramente são os nossos. Nesse particular foi duplamente eficaz, pois tanto contribui à importação de doutrinas que nada têm a ver com nossas realidades, como, pelo seu uso prestigioso, impede que um pensamento autônomo e sério se desenvolva."(Santos, Milton, Espaço e Sociedade, Petrópolis, Vozes, 1979, p. 37)

(3) Veja a respeito, de Milton Santos, Por uma Economia Política da Cidade, São Paulo, Hucitec, 1994; e Metrópole Corporativa Fragmentada-O Caso de São Paulo, São Paulo, Nobel/ Secretaria de Estado da Cultura, 1990. 
mento de uma democracia restrita, diluindo propostas políticas oposicionistas, nascidas de uma sociedade civil que emergia, produto, inclusive da diferenciação sócio-econômica, que o desenvolvimento industrial consolidava, e da identidade proletária que dela derivava. A distensão política exigia o urbano ordenado, imposto, organizado, que os investimentos em infra-estrutura urbana, acentuados no período anterior, tornava possível. ${ }^{4}$ Nos termos de Milton Santos, não superamos o desenvolvimento da cidade corporativa; as alternativas políticas noutra direção estão por se consolidar e sofrem a força da tradição da presença do moderno e do progresso, enquanto produção do Estado voltada para a infra-estrutura urbana, que desiste de grande massa da população urbana. É a força de uma face da pobreza planejada.

O Estado nacional é a mediação crucial entre as condições históricas da atividade mundial e as condições da vida local, no que respeita às grandes cidades, e a partir delas, sob seu modelo, quanto às demais cidades e regiões. Uma política econômica modifica não só as condições da produção agrícola e industrial, as estruturas de circulação e mesmo as de consumo, como, dessa forma, afeta a importância das cidades e os dados da organização do espaço. ${ }^{5}$ Estamos diante do impaçto da modernização tecnológica nos países pobres e da série de obrigações dela decorrentes, envolvendo o aparetho do Estado.

Retomemos o argumento sobre a macrocefalia ou sobre as transformações recentes nas antigas relações entre cidades e espaços circundantes, que podiam supor economias regionais. A concentração econômica e espacial dos capitais, com a internalização da divisão internacional do trabalho, na fase técnico-científica atual, debilita a noção clássica de região. "Do ponto de vista dos fluxos de mercadorias, o país inteiro se torna 'a região' do seu 'centro'". ${ }^{6}$ A rede urbana e seu estudo não se caracteriza por mais um enfoque, tradicional em geografia, mais que isso faz parte do processo de desvendamento dos termos da organização do es- paço, nessa segunda metade do século XX, nos países pobres. Não cabe a compreensão da cidade isoladamente. "Na realidade, a unidade do estudo geográfico, é a rede urbana... talvez nos leve a discernir uma tipologia de formas de transição ou passagem e mesmo a estabelecer uma prospectiva." " Uma definição da rede urbana, diante de seu significado metodológico, seria apresentá-la como “... o resultado de um equilíbrio instável de massas e de fluxos cujas tendências à concentração e à dispersão variam no tempo e estão em relação com os dados estruturais e técnicos de ordem econômica, sóciocultural e política." "Trata-se de uma combinação que está sempre a evoluir, cujas formas têm algo de provisório. Haveria uma dialética entre os fatores de concentração e de dispersão. "As estruturas monopolísticas constituem um fator de concentração, a difusão da informação e do consumo desempenham um papel de dispersão..."

Distingue cidades locais, cidades regionais, metrópoles incompletas e completas, numa classificação básica da organização do espaço recente. As metrópoles seriam responsáveis pela macroorganização do espaço, embora, a primeira delas, para exercer a totalidade de suas funções, dependesse de contribuições externas, não respondendo com meios próprios às necessidades econômicas e sociais, fruto do atraso de sua industrialização, bem como das formas que essa industrialização assume.

(4) Damiani, Amélia Luisa, A Cidade (Des)Ordenada, tese de doutoramento, FFLCH, USP, Departamento de Geografia, 1993.

(5) Santos, Milton, Ensaios sobre a Urbanização LatinoAmericana, São Paulo, Hucitec, 1982, p. 71.

(6) Santos, Milton, Espaço e Método, São Paulo, Nobel, 1985, p. 66 .

(7) Santos, Milton, O Trabalho do Geógrafo no Terceiro Mundo, São Paulo, Hucitec, 1986, p. 81.

(8) Op. Cit. p. 101.

(9) Santos, Milton, OEspaço Dividido-Os Dois Circuitos da Economia Urbana dos Países Subdesenvolvidos, Rio de Janeiro, Francisco Alves, 1979, p. 222. 
Toda ordem de dependência é típica dos termos de reprodução dos países pobres na economia mundial.

De qualquer maneira, um pressuposto da existência de um sistema de cidades é a integração nacional pelos transportes. E, ao mesmo tempo, desencadeia o sentido primordial dos fluxos: “...em consequiência do período tecnológico e em função da falta de elasticidade do emprego, as pessoas deixam o campo sem parar necessariamente na cidade local. As facilidades de transportes impelem os migrantes potenciais para as cidades regionais onde o setor terciário é mais elástico e, principalmente, direto para as grandes cidades." 10 As cidades regionais tornam-se cidades intermediárias, "seu poder de comando e sua influência sobre a região diminuem e ela (a cidade intermediária) se torna, cada vez mais, um relé da metrópole." "Há o desmantelamento da rede urbana, em sua concepção tradicional, pois as relações se fazem, primordialmente, direto com as grandes cidades. Pode-se falar em simultaneidade entre os lugares, “... o tempo que está em todos os lugares é o tempo da metrópole, que transmite a todo o território o tempo do Estado e o tempo das multinacionais e das grandes empresas." Todos os outros pontos da rede urbana são marcados por tempos subalternos e diferenciados. ${ }^{12}$ A macrocefalia é um produto das modernas relações econômicas, nos termos como essas se desenvolvem, no conserto de trocas desiguais, envolvendo os países pobres, não representa uma anomalia atrasada, ou uma patologia avessa à modernidade. O impacto das modernizações, nos países subdesenvolvidos apresenta-se, frequientemente, pontual; há uma inércia considerável em sua difusão. ${ }^{13}$ Existe, em princípio, uma concentração mais acentuada que aquela registrada nos países desenvolvidos, como reflexo da não fluidez dos elementos do progresso - como economias de escala, mercado consumidor amplo, etc..$-^{14}$ Nestes pontos, existe o acúmulo das forças vivas da nação.

Em O Espaço Dividido, Milton Santos reconhece cinco períodos de modernização, que defini- riam generalizações de inovações, a partir das regiões polarizadoras, em direção aos sistemas dominados, também chamados subsistemas subordinados. Trata-se de uma sucessão de modernizações, referentes aos períodos da história econômica do sistema mundial. O impacto das modernizações é diverso, pois além das forças externas, depende das forças existentes nos espaços atingidos. "Há formas diferentes de combinação entre um novo modelo de produção, distribuição e consumo e a situação preexistente... trata-se de uma aceitação dos elementos de modernização 'em diferentes graus". ${ }^{15}$ Assim, configura-se a formação dos espaços periféricos, os espaços do Terceiro Mundo. As modernizações como projeções do sistema mundial, também, tomaram formas diferentes, nos espaços dependentes, nos diferentes períodos de sua difusão no mundo. Definem-se como modernização comercial, modernização industrial, modernização tecnológica, a última sucedendo a Segunda Guerra

(10) Op. Cit. p. 238

(11) Op. Cit. p. 243

(12) Santos, Milton, Técnica Espaço Tempo, São Paulo, Hucitec, 1994, p. 155. Ainda quanto ao Brasil, elucida: "Houve, ao longo da história brasileira, quatro momentos do ponto de vista do papel e significação das metrópoles. Quando o Brasil urbano era um arquipélago, pela ausência de comunicações fáceis entre as metrópoles, estas apenas comandavam uma fração do território, sua chamada zona de influência. Num segundo momento, há luta pela formação de um mercado único com uma integração territorial apenas no Sudeste e no Sul. Um terceiro momento é quando um mercado único nacional se constitui. E o quarto momento, o atual, conhece um ajustamento à crise desse mercado, que é um mercado único, mas segmentado, único e diferenciado, um mercado hierarquizado e articulado pelas firmas hegemônicas, nacionais e estrangeiras, que comandam o território com apoio do Estado." (p. 154)

(13) Op. Cit. nota 8, p. 106.

(14) Santos, Milton, A Urbanização Desigual-A Especificidade do Fenômeno Urbano em Países Subdesenvolvidos, Petrópolis, Vozes, 1980, p. 105/116.

(15) Op. Cit. nota 10, p. 42. 
Mundial, mais exatamente, posterior aos anos 50; a primeira começando em fins do século XV. Nem todos os países subdesenvolvidos foram atingidos pelos efeitos de todas essas modernizações. $\mathrm{O}$ atual período tem enorme capacidade de revolucionarização, difundindo, pelos países periféricos, duas variáveis elaboradas no centro do sistema: a informação e o consumo. Há uma verdadeira mundialização dos lugares, formando lugares especializados e complexos (as metrópoles e as grandes cidades), contudo ostentando, no caso dos países do Terceiro Mundo, muitas vezes, uma modernização incompleta, seletiva e perversa, remetendo ao caráter corporativo de sua urbanização, já mencionado, devido às exigências da modernidade contemporânea, assumidas pelos Estados pobres.

"As metrópoles do Terceiro Mundo são uma cristalização de nova lógica em pontos do território, ao mesmo tempo econômica, política, social e geográfica, correspondente ao novo momento histórico. É aí que confluem resultados contraditórios de um processo de modernização que impõe novas formas de atraso."16 Há uma expansão da pobreza, concomitante à modernização das atividades, conduzindo a uma "involução metropolitana". Existe crescimento, mas este é paralelo à baixa do rendimento médio e à expansão de empregos mal remunerados, refletindo nas condições de vida de amplas massas de população.

"A modernização da produção industrial, representada pelas multinacionais e conglomerados, e a modernização da agricultura, de modo geral, induzem à queda do emprego nesses setores e ao êxodo rural e, conseqüentemente, ao aumento da população urbana, com o desenvolvimento das grandes cidades." 17

Concomitantemente, há uma diversificação da produção, com a proliferação de um corpo de empresas e estabelecimentos de diferentes tamanhos, com base em técnicas e níveis organizacionais, os mais diversos. Tanto a população mais pobre, como a classe média, com o aumento e a diversificação do consumo, acabam por exigir essa presença, con- figurando uma segmentação da economia urbana. "A involução metropolitana e a segmentação da economia são, portanto, fenômenos correlatos..."18

A existência de dois circuitos da economia urbana já havia, há muito, sido definida por Milton Santos, francamente, formulada no livro O Espaço Dividido. Como dois subsistemas, o circuito superior e o circuito inferior, ambos, embora diversos, por sua utilização da tecnologia, sua forma de organização e toda sua estrutura de produção e distribuição, atingindo camadas sociais consumidoras diferentes, não são estritamente opostos, mas aparecem como frutos dos termos da modernização e mantêm inúmeras relações, por exemplo, vendedores ambulantes do circuito inferior trabalharem, periodicamente, em fábricas para suplementar sua renda; alguns dos fornecimentos do circuito inferior provir direta ou indiretamente dos chamados setores modernos da economia, etc. "O termo circuito "demonstra melhor o fluxo interno entre os dois subsistemas"". ${ }^{19}$ Definir o circuito inferior como tradicional, assim, é equivocado. $\mathrm{O}$ sistema urbano, dependente, por sua vez, de outros sistemas, apresenta mais de um subsistema econômico. A contemporaneidade desses diversos tempos econômicos e sociais, nascida no seio da modernização tecnológica, aparece como alternativa a uma visão de que os países subdesenvolvidos viveriam uma situação dual, com a presença do moderno e do tradicional, e a superação dessa dualidade levaria os mesmos à situação dos países desenvolvidos. Um equívoco conveniente na interpretação da urbanização dos países do Terceiro Mundo.

Trata-se, também, de esclarecer o significado do circuito superior marginal, cuja presença neces-

(16) Por una Economia Política da Cidade, p. 79.

(17) Op. Cit. p. 94.

(18) Op. Cit. p. 95.

(19) Santos, Milton, Pobreza Urbana, São Paulo, Hucitec, 1979 , p. 37. 
sita ser desvendada. O "... circuito superior marginal trabalha segundo parâmetros modernos, o que o aproxima do circuito superior, mas é, em grande parte, resposta às necessidades de consumo localmente induzidas, o que o aproxima do circuito inferior.

O circuito superior marginal aparece, nas cidades do Terceiro Mundo, ao mesmo tempo como um obstáculo à oligopolização completa da economia e como uma de suas condições." ${ }^{20} \mathrm{O}$ circuito superior se serve dele para abastecimento de bens e serviços intermediários, ou deixa para ele faixas de mercado e áreas geográficas onde não quer atuar.

A pobreza urbana, então, é obra dessa modernização, e, ao mesmo tempo, também, justifica sua singularidade nos países do Terceiro Mundo. Mais do que nas demais cidades modernizadas, e o sentido é o da desconcentração das atividades econômicas modernas, as grandes cidades conhecem a composição perversa entre a modernização e a pobreza e as atividades econômicas pobres, sugerindo a designação de "involução metropolitana". Uma economia política da cidade passa a ser fundamental, não somente uma economia política da urbanização, que remeta à divisão social e territorial do trabalho. A segunda associaria o conhecimento dos efeitos da divisão do trabalho sobre as condições locais do mercado, permitindo desvendar a singularidade das novas formas de atraso.

Mesmo metrópoles como São Paulo, que se define como metrópole transacional, assentada na sua condição de metrópole industrial, passando a ter um papel de comando que é devido a formas superiores de produção não material, envolvendo a informação - essa condição de metrópole global, de São Paulo, na sua terceira etapa de mundialização remete aos anos posteriores a 1960 -, reforça o caráter geograficamente concentrado da produção mais moderna. Se a produção material tende a se dispersar, os novos terciários têm tendência concentradora, a interdependência com relação às áreas centrais não se dilui, e a urbanização é sempre seletiva e perversa, nos termos de uma econo- mia urbana segmentada, cujo foco principal é a grande cidade, e a partir dela se generaliza.

Ao invés de distinguir as cidades por dados demográficos brutos, é preciso considerar que as enormes diferenças de renda, que definem a sociedade global dos países subdesenvolvidos, "têm consequiências notáveis sobre a organização do espaço", na qualificação das atividades desenvolvidas, na seleção das mesmas, com tendências a uma hierarquização. ${ }^{21}$ Disparidades de renda entre os indivíduos, disparidades regionais definem, de alguma forma, o sentido das atividades terciárias, que passam a ser definitivamente concentradas, a modernização dos transportes acelera essa tendência tornando as relações mais numerosas e menos custosas, por intermédio das grandes cidades, onde também florescem atividades terciárias superiores. ${ }^{22}$

De um lado, há uma rígida vocação internacional, marcada por espaços detalhadamente preparados para exercer funções mais precisas, numa reprodução crua de segregação espacial, numa nova rigidez metropolitana, com objetos geográficos, cujo funcionamento é, cada vez mais, interdependente e sistêmico, no quadro de um meio técnicocientífico-informacional, que deixa de ser plástico; por outro lado, as grandes cidades são dotadas de flexibilidade, permitindo a atuação de todos os tipos de capital e de trabalho, são formas não atualizadas da economia não hegemônica, de caráter endógeno, como verdadeiros traços da flexibilidade tropical. ${ }^{23}$ Trata-se da contemporaneidade de “...áreas 'luminosas', constituídas ao sabor da modernidade e que se justapõem, superpõem e contrapõem ao resto da cidade onde vivem os pobres, nas zonas urbanas 'opacas"'. Os últimos são espaços aproximativos, abertos, não racionalizados ou

(20) Op. Cit. nota 17 , pp. 96/97.

(21) Op. Cit. nota 8, pp. 106/107.

(22) Santos, Milton, Espaço e Sociedade, Petrópolis, Vozes, 1979, p. 60.

(23) Op. Cit. nota 13 , pp. 77/78/79/80. 
racionalizadores, espaços da lentidão; os outros são frutos da exatidão e da vertigem. A força é dos lentos, dos pobres e migrantes, num espaço "inorgânico", aliado da ação, que torna possível a solidariedade na cidade, contraposto ao dos ricos, invadidos por uma racionalidade que chega aos arcanos da vida, empobrecidos e privados de orientação para o futuro, que vivem a velocidade e a mobilidade e vêem pouco, comungando imagens prefabricadas, numa grande perdição ${ }^{24}$ Essa é uma face do conteúdo geográfico do cotidiano, que contribui à necessária teorização da relação entre espaço e movimentos sociais. ${ }^{25}$

Duas referências fora da obra de Milton Santos, uma delas, inclusive, por ele mencionada, $\mathrm{O}$ Capítulo Inédito de karl MarX, merecem ser consideradas, pois esclarecem a questão das múltiplas temporalidades, fora de uma visão dicotômica, que tanto preocupa o autor e o remete a uma construção alternativa, que tentamos resgatar em alguns de seus aspectos.

O Capítulo Inédito discute a subsunção formal e real do trabalho ao capital, a primeira preservando processos de trabalho preexistentes, sob a direção do capital, quando "só se pode produzir mais valia através do prolongamento do tempo de trabalho, isto é, sob a forma da mais-valia absoluta", contrastando com o modo de produção especificamente capitalista, referente a segunda, que equivale a uma revolução total, que "revoluciona não só as relações entre os diversos agentes da produção, mas simultaneamente, a índole desse trabalho e a modalidade real do processo de trabalho total", e que sugere a extração da mais-valia relativa. ${ }^{26}$ Somente quando consideradas isoladamente, como formas separadas no interior da produção capitalista, como existências separadas, uma apenas precede a outra, a primeira sendo precursora da segunda; de outra forma, é possível e necessário considerar que "a segunda, possa constituir, por sua vez, a base para introdução da primeira em novos ramos da produção." ${ }^{27}$

A noção de formação econômico-social, tanto em Marx, como em Lênin, esclarece que a base de desenvolvimento do capitalismo não é o desenvolvimento igual, mas a lei do desenvolvimento desigual, que, por sua vez, não pode ser interpretada na perspectiva economicista, que redunda na dicotomia entre o desenvolvimento e o subdesenvolvimento, reduzindo "a qualidade das contradições que integram e opõem diferentes sociedades à mera gradação da riqueza... Na verdade, a 'lei do desenvolvimento desigual tem uma multiplicidade de sentidos e aplicações'. Na interpretação de Lefebvre, 'ela significa que as forças produtivas, as relações sociais, as superestruturas (políticas, culturais) não avançam igualmente, simultaneamente, no mesmo ritmo histórico"'. Trata-se da coexistência dos tempos históricos. ${ }^{28}$

Embora Milton Santos insista numa leitura sistêmica, diferente da abordagem dos dois autores acima mencionados, é evidente que o sentido da interpretação se preserva, isto é, transpõe uma análise dicotômica, que sempre feriu a compreensão dos países do Terceiro Mundo e confundiu o entendimento crítico do capitalismo no mundo, sujeitando-se às suas formas de reprodução, como foi avaliado no início deste texto. Os termos da modernização incompleta e perversa, que atinge os países pobres, e os resíduos transformadores, no interior da pobreza e dos espaços pobres demonstram o exercício da lei do desenvolvimento desigual, para além de uma leitura economicista. Aqui, admite-se o desencontro entre o econômico e o social, um não sendo, estritamente, o reflexo do outro. E, ainda, que o social, "marginalizado" do econômico mais moderno, não

(24) Op. Cit. nota 13 , Capítulo 8.

(25) Op. Cit. nota 13, p.109.

(26) Marx, Karl, O Capital, Livro l, Capítulo Vl (Inédito), São Paulo, Ciências Humanas, 1978, pp. 52/53.

(27) Op. Cit. p. 56.

(28) Martins, José de Souza (org.), Henri Lefebvre e o Retorno à Dialética, São Paulo, Hucitec, 1996, Capítulo 1, As Temporalidades da História na Dialética de Lefebvre, de José de Souza Martins, pp. 16/17/18/20. 
representa, exatamente, atraso, "ações arcaicas, irracionais e ineficientes", o que manteria um caráter etnocêntrico e ideológico ${ }^{29}$, mas revela possibilidades. Nos termos de uma pesquisa que ora desenvolvo, não há uma condução linear entre a sobrevivência e a vida, e é preciso, no caso dos países pobres, diante de sua especificidade, para produzir um conhecimento crítico, enfrentar a complexidade entre sobrevivência e vida e o significado da vida urbana nessa configuração complexa.

A análise sistêmica, pela qual opta o Prof. Milton Santos, durante todo o percurso de sua construção, pode apresentar um grave problema que é aquele de submeter a história, transformá-la num resíduo, e de hipostasiar a estrutura, intelegível, exigida "pelas técnicas, pelos dispositivos e redes de circulação, de comunicação, de informação, do governo e do Estado" ${ }^{30}$. Não há como negar que nossa época evoca essa possibilidade e ela representa o risco do fantasma da tecnocracia: o império da coerência, do equilíbrio, da coesão, da articulação, da racionalidade e da ciência que se impõe metafisicamente, sob a égide dos tecnocratas. Ideologia e ciência, mais que nunca, misturam-se. Saber e poder compõem um par indissociável. Muitas vezes, o rigor da articulação de uma multiplicidade de sistemas e subsistemas, para explicar a história mundial recente, em sua obra, sugere, potencialmente, esse caminho.

Mas, é possível acordar para um outro teor de sua análise sistêmica, mais dialético, o de que convive-se, o tempo todo, com a estrutura enquanto "um equilíbrio precário entre hierarquias múltiplas e móveis", Aqui, ao invés de se comprometer a história, vislumbra-se a ela "como processo de perpétuas estruturações e desestruturações" ${ }^{31}$. Neste caso, a análise dialética prevalece sobre a estrutural, e não pode ser concebida sem as contradições, que geram a destruição das estruturas, definidas como provisórias. Para conservar essa possibilidade de leitura, na obra do Prof. Milton Santos, é preciso considerar, primeiro, que ele é um estudioso da técnica e de seu poder no mundo de hoje, e para não subestimála, acaba por avaliar a pertinência da análise dos sistemas, exatamente, para desvendar esse poder, já que a lógica da técnica é, essencialmente, compatível com a do sistema. Uma análise sistêmica entra nas entranhas da técnica e de suas consequïências. Se esta é a única forma possível, francamente, minha formação faz duvidar, mas não chega e nem pode alimentar, por isso, preconceitos. Segundo, porque reconhece uma característica primordial de nossa época, a de que ela não se esgota num único sistema, mas em múltiplos subsistemas, relacionados complexamente, permitindo, inclusive, a coexistência c'e temporalidades diversas, perversamente vividas. Não sugere quaisquer formas de dualismos, ao contrário, insurge contra eles, aparecendo como alternativa crítica à análise etnocêntrica dos países pobres. Em terceiro lugar, porque não submete a ação ao sistema dos objetos, embora reconheça o perigoso avanço da conjugação entre objetos e ações. Diz: "para a maior parte da humanidade, elas (as ações) não são informadas de modo endógeno, mas informadas de fora... Uma ação codificada, presidida por uma razão formalizada, ação que não é isolada, e que arrasta, ação que se dá em sistema, cujo lubrificante maior passou a ser, talvez, não a produção, mas sim a comunicação, tem o papel fundamental na organização da vida coletiva e na condução da vida individual. Entender todo esse processo torna-se crucial, tanto na interpretação do que a realidade é, como no esforço para mudá-la." ${ }^{32}$ Estudamos, aqui, os limites crassos das coações. E, ao mesmo tempo, e inversamente, essa racionalidade dominante não exclui a prática de outras e novas racionalidades, "mais consentâneas com a ordem desejada" 33 , próprias do lugar e do cotidiano, "que contém a variedade das coisas e das

(29) Op. Cit. nota 20, p. 53.

(30)Lefebvre, Henri, L'ldéologie Structuraliste, Paris, Anthropos, 1971, pp. 34/35.

(31) Op. Cit. pp. $36 / 37$.

(32) Op. Cit. nota 13, pp. 102/103.

(33) Op. Cit. nota 13, p. 58. 
ações, incluindo, também, a multiplicidade infinita de perspectivas...

A vida não é um produto da Técnica, mas da Política, a ação que dá sentido à materialidade." ${ }^{34}$
Os homens pobres, comuns e lentos, como já mencionado, que guardam totalizações do passado, são resistentes. ${ }^{35}$

\section{RÉSUMÉ}

Cet article discute la possibilité d'une teorie sur l'urbanization des pays pauvres, écrit a propos d'un séminaire inspiré dans l'oeuvre de Milton Santos.

L'oeuvre de Milton Santos, inachevée, dans la mesure qu'il continue sa reflexion avec intensité, et, au même temps, complexe, elle contient, surément, une teorie critique de l'urbanization dans les pays pauvres. Quelques éléments de cette teorie sont-ils ici exposés, malgré les dificultés d'attendre la précision et la cer- titude des concepts. La problématique donc est immense; les concepts s'enchainent dans une teorie et, lorsqu'on écrit une interprétation, elle peut conduire le risque de banalisation. Malgré cela, l'importance et l'extension de l'urbain, dans un monde où l'urbanization se déploie, les reproductions et les actualisations des interprétations malthusiennes sur cet phénomène, surtout quand on parle des pays pauvres, et les écrits de Milton Santos les dépassant, nous ont fait en revenir.

(34) Op. Cit. nota 13, p. 39.

(35) Em seu último livro, A Natureza do Espaço-Técnica e Tempo. Razão e Emoção ( São Paulo, Hucitec, 1996), Milton Santos aprofunda francamente essas concepções. Este artigo não pode contar com essa última reflexão. Eis aqui, apenas, a recomendação de sua leitura necessária para a elucidação do tema proposto. 